\title{
Evolution of SIV toward RANTES resistance in macaques rapidly progressing to AIDS upon coinfection with HHV-6A Angélique Biancotto ${ }^{1,2}$, Jean-Charles Grivel ${ }^{1}$, Andrea Lisco ${ }^{1}$, Christophe Vanpouille ${ }^{1}$, Phillip D Markham ${ }^{3}$, Robert C Gallo ${ }^{4}$, Leonid B Margolis*1 and Paolo Lusso*5,6,7
}

Address: ${ }^{1}$ Laboratory of Molecular and Cellular Biophysics, National Institute of Child Health and Human Development, Bethesda, MD 20892, USA, ${ }^{2}$ Center for Human Immunology, National Heart, Lung and Blood Institute, Hematology Branch, Bethesda, MD 20892, USA, ${ }^{3}$ Advanced Bioscience Laboratories, Kensington, Maryland 20895, USA, ${ }^{4}$ Institute of Human Virology, University of Maryland Biotechnology Institute, Baltimore, MD 21202, USA, ${ }^{5}$ Unit of Human Virology, DIBIT San Raffaele Scientific institute, Milano, 20132, Italy, ${ }^{6}$ Department of Medical Sciences, University of Cagliari School of Medicine, Cagliari, 09149, Italy and ${ }^{7}$ Laboratory of Immunoregulation, NIAID, NIH, Bethesda, MD 20892, USA

Email: Angélique Biancotto - biancoa@nhlbi.nih.gov; Jean-Charles Grivel - grivelj@cc1.nichd.nih.gov; Andrea Lisco - liscoa@mail.nih.gov; Christophe Vanpouille - vanpouic@mail.nih.gov; Phillip D Markham - Phillip.MARKHAM@ablinc.com;

Robert C Gallo - snallo@ihv.umaryland.edu; Leonid B Margolis* - margolil@mail.nih.gov; Paolo Lusso* - plusso@niaid.nih.gov

* Corresponding authors

Published: 2 July 2009

Retrovirology 2009, 6:61 doi:|0.|1186/|742-4690-6-6I

This article is available from: http://www.retrovirology.com/content/6/I/6I

(c) 2009 Biancotto et al; licensee BioMed Central Ltd.

This is an Open Access article distributed under the terms of the Creative Commons Attribution License (http://creativecommons.org/licenses/by/2.0), which permits unrestricted use, distribution, and reproduction in any medium, provided the original work is properly cited.

\begin{abstract}
Background: Progression to AIDS is often associated with the evolution of HIV-I toward increased virulence and/or pathogenicity. Evidence suggests that a virulence factor for HIV-I is resistance to CCR5-binding chemokines, most notably RANTES, which are believed to play a role in HIV-I control in vivo. HIV-I can achieve RANTES resistance either by phenotypic switching from an exclusive CCR5 usage to an expanded coreceptor specificity, or by the acquisition of alternative modalities of CCR5 usage. An infectious agent that might promote the evolution of HIV-I toward RANTES resistance is human herpesvirus 6A (HHV-6A), which is frequently reactivated in HIV-I-infected patients and is a potent RANTES inducer in lymphoid tissue.
\end{abstract}

Results: SIV isolates obtained from pig-tailed macaques ( $M$. nemestrina) after approximately one year of single infection with

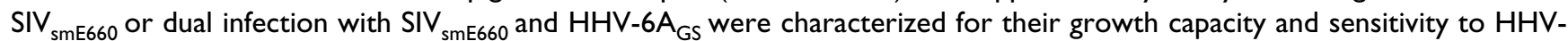
6A- and RANTES-mediated inhibition in human or macaque lymphoid tissues ex vivo. Four out of $4 \mathrm{HHV}-6 \mathrm{~A}-$ coinfected macaques, all of which progressed to full-blown AIDS within 2 years of infection, were found to harbor SIV variants with a reduced sensitivity to both HHV-6A and RANTES, despite maintaining an exclusive CCR5 coreceptor specificity; viruses derived from two of these animals replicated even more vigorously in the presence of exogenous HHV-6A or RANTES. The SIV variants that emerged in HHV-6A-coinfected macaques showed an overall reduced ex vivo replication capacity that was partially reversed upon addition of exogenous RANTES, associated with suppressed IL-2 and enhanced IFN- $\gamma$ production. In contrast, SIV isolates obtained from two singly-infected macaques, none of which progressed to AIDS, maintained HHV-6A/RANTES sensitivity, whereas the only AIDS progressor among singly-infected macaques developed an SIV variant with partial HHV-6A/RANTES resistance and increased replication capacity, associated with expanded coreceptor usage.

Conclusion: These results provide in vivo evidence of SIV evolution toward RANTES resistance in macaques rapidly progressing to AIDS. RANTES resistance may represent a common virulence factor allowing primate immunodeficiency retroviruses to evade a critical mechanism of host antiviral defense. 


\section{Background}

Although HIV-1 is the necessary and sufficient causative agent of AIDS [1], progression to full-blown immunodeficiency is associated with de novo infection with or reactivation of a wide variety of other microbial agents. While coinfection with some agents has been associated with reduced HIV-1 loads and delayed AIDS progression [2-5], most of these microbes accelerate the clinical course either by inducing opportunistic diseases or by enhancing the level of HIV-1 replication [6]. However, the mechanisms whereby these agents operate in vivo remain largely unknown. Several lines of clinical and experimental evidence suggest that human herpesvirus 6 (HHV-6), particularly its A variant (HHV-6A), acts as an accelerating factor in HIV-1 disease [7]. In vitro, HHV-6A was shown to: i) replicate primarily in $\mathrm{CD} 4{ }^{+} \mathrm{T}$ cells and cause their destruction in synergy with HIV-1 [8]; ii) transactivate the HIV-1 long terminal repeat [9]; iii) induce de novo CD4 expression and HIV-1 susceptibility in otherwise HIV-refractory cells such as CD8 ${ }^{+} \mathrm{T}$ lymphocytes and NK cells [10,11]; and iv) augment the release of HIV-1-enhancing inflammatory cytokines [12]. In vivo studies have documented: i) widespread HHV-6 infection in patients with full-blown AIDS at post-mortem examination $[13,14]$; ii) frequent reactivation of HHV-6 in early symptomatic HIV-1infected subjects [15]; iii) vigorous HHV-6 replication in lymph nodes of HIV-1-infected subjects, associated with an increased local HIV-1 load [16,17]; and iv) accelerated progression of HIV-1 disease in infants who acquire HHV6 within the first year of life [18]. In addition, we recently provided evidence that in vivo coinfection with HHV-6A accelerates the course of simian immunodeficiency virus (SIV) disease in pig-tailed macaques (M. nemestrina) [19].

The availability of the experimental model of pig-tailed macaques coinfected with SIV and HHV-6A gave us a unique opportunity to investigate the effects of a diseaseaccelerating viral cofactor on the evolution of SIV during the course of AIDS progression. We report here that rapidly progressing HHV-6A-coinfected macaques invariably harbored RANTES-resistant and even RANTES-inducible SIV variants, which nevertheless maintained a CCR5dependent phenotype. These results provide the first demonstration of SIV evolution toward RANTES resistance under the influence of a coinfecting microbe, illustrating a potential mechanism for the accelerated progression to full-blown AIDS seen in HHV-6A-coinfected macaques.

\section{Methods}

\section{SIV isolates}

SIV was isolated from 7 macaques, three singly infected with SIV, strain smE660 (\#301, 303, 307), and 4 coinfected with SIV and HHV-6A, strain GS (\#313, 315, 316, $317)$, after 10 to 12 months of infection. For this purpose, freshly isolated PBMC were obtained from each animal and cultured in vitro after stimulation with PHA and IL-2, leading to the appearance of increasing levels of SIV p27 antigen in the culture supernatants, as assessed by ELISA. Virus isolation was attempted from a fourth singlyinfected animal (\#299), but it was unsuccessful. The SIV isolates were cleared of cells and cellular debris by centrifugation, characterized for SIV p27 antigen content and frozen in aliquots at $-80^{\circ} \mathrm{C}$. HHV- 6 contamination of the SIV stocks was excluded using a real-time PCR assay with a lower sensitivity of $<10 \mathrm{HHV}-6$ genome copies/ml [20].

\section{Ex vivo lymphoid tissue culture and infection}

Human tonsils were received from the Children's National Medical Center, Washington, DC, according to an IRB-approved protocol, and tissue blocks were processed and infected as described [21,22]. Lymph nodes from SIV-seronegative macaques (M. mulatta) were processed likewise. In a typical experiment, $3.3 \mu$ l of clarified stock of SIV ( $\sim 1 \mathrm{ng}$ of p27) were applied onto the top of each tissue block. Infected tissue blocks were cultured for 12 days and SIV replication was assessed by a commercial p27 ELISA (Beckman-Coulter, Miami, FL). Recombinant human RANTES (Peprotech, Rocky Hill, NJ) was added to the culture media at $100 \mathrm{nM}$ for 18 hour prior to SIV infection and maintained at the same concentration thereafter. The medium was changed every 3 days and RANTES was re-added at every medium change. For HHV-6A infection, the tissue blocks were inoculated with $10 \mu \mathrm{l}$ of the viral stock, strain GS [23], containing $\sim 10^{6}$ cell culture infectious doses $/ \mathrm{ml}$, produced by infecting PHA-activated human PBMC and by collecting cell-free culture supernatants at the time of peak cytopathic effect (typically at day 6 to 8 post-infection) [8].

\section{Infection of human PBMC}

PBMC obtained from randomly selected healthy donors or from a homozygous CCR $5-\Delta 32^{+/+}$donor were activated with phytohemagglutinin-P (PHA-P) (Difco, Franklin Lakes, NJ) at $2 \mu \mathrm{g} / \mathrm{ml}$ in RPMI 1640 supplemented with $15 \%$ FBS and $100 \mathrm{U} / \mathrm{ml}$ rhIL-2 (Roche Molecular Biochemicals, Nutley, NJ). The cells were then exposed to SIV for 3 hours at the multiplicity of infection of 0.01 , washed and re-cultured in medium containing IL-2.

\section{Measurement of cytokine production}

Cytokine levels were measured using a multiplex bead array on a Luminex-100 platform. All antibodies and cytokine standards were purchased from R\&D Systems (Minneapolis, $\mathrm{MN}$ ). Luminex bead sets were coupled to cytokine-specific antibodies, washed and kept at $4^{\circ} \mathrm{C}$ until use. All the assay procedures were performed in PBS supplemented with 1\% normal mouse serum, 1\% normal goat serum, and $20 \mathrm{mM}$ Tris- $\mathrm{HCl}(\mathrm{pH} 7.4)$. The assays were performed using 1,200 beads per set per well in a total volume of $50 \mu \mathrm{l}$. Fifty $\mu \mathrm{l}$ of each sample were added 
to the well and incubated overnight at $4{ }^{\circ} \mathrm{C}$ in a Millipore Multiscreen plate. After 3 washes with PBS, the beads were incubated with biotinylated polyclonal antibodies for 1 hour at room temperature, then washed 3 times with PBS, resuspended in $50 \mu \mathrm{l}$ of assay buffer, and treated with streptavidin-PE (Molecular Probes, Carlsbad, CA) at 16 $\mu \mathrm{g} / \mathrm{ml}$. The plates were read on a Luminex-100 platform. For each bead set, a total of 61 beads were collected.

\section{Statistical analyses}

Due to extensive donor-to-donor variation in this model $[22,24]$, data were normalized as percent of controls. Statistical analyses included the calculation of mean and SE and $P$ values by use of multiple comparison tests (2-way ANOVA test or a paired student t-test). ELISA data were analyzed with the Deltasoft software (version 3.0; BioMetallics); Luminex data with the Bioplex Manager software (version 4.0; Bio-Rad) using the median fluorescence intensity recorded for 61 beads from each set.

\section{Results}

Altered replicative capacity of SIV isolated from $\mathrm{HHV}-6 \mathrm{~A}-$ coinfected macaques

For the purpose of this study, we selected 7 SIV isolates obtained after approximately 1 year of inoculation from three macaques singly-infected with SIV and 4 macaques coinfected with HHV-6A and SIV. By ultra-sensitive realtime PCR, we first ascertained that none of the SIV stocks was contaminated by HHV-6 (not shown). Human and macaque lymphoid tissues were exposed to the SIV isolates without exogenous stimulation. For each viral isolate, tissues derived from 11 to 15 different human donors were tested; for each tissue, 27 blocks were infected ex vivo with comparable doses of each viral stock, and the presence of p27 viral protein in the tissue culture supernatant was measured by ELISA every 3 days. As shown in Fig. 1A, all 7 SIV isolates were able to replicate in human lymphoid tissue. However, the cumulative level of virus replication was significantly higher for SIV isolates derived from singly-infected animals (mean $=19 \pm 3 \mathrm{ng} / \mathrm{ml} ; \mathrm{n}=$ 37) compared to those derived from HHV-6A-coinfected animals (mean $=5 \pm 1 \mathrm{ng} / \mathrm{ml} ; \mathrm{n}=51)\left(P=1 \times 10^{-5}\right)$ (Fig. 1B). Of note, the highest replication levels were observed with isolate \#303, obtained from the only animal in the singly-infected group which progressed to full-blown AIDS before termination of the in vivo study [19].

Next, we assessed the ability of two representative SIV isolates to replicate in macaque lymphoid tissue, which is more relevant to the in vivo model from which they were derived. The two isolates that exhibited the most divergent replication capacities in human lymphoid tissue were selected (\#303, derived from a singly-infected animal, and \#316 derived from an HHV-6A-coinfected animal). As shown in Figure 1C, the average replication levels of these two isolates in macaque lymphoid tissue were strikingly different $(94.0 \pm 3 \mathrm{ng} / \mathrm{ml}$ for \#303, and $2.2 \pm 0.2 \mathrm{ng} / \mathrm{ml}$ for \#316 $(\mathrm{n}=3)$ ) with a pattern similar to that observed in human lymphoid tissue, thus ruling out the presence of selective inhibitory mechanisms in human tissue and confirming that the replicative capacity of SIV passaged in vivo with HHV-6A was intrinsically altered.

\section{Resistance of SIV isolates derived from HHV-6A-coinfected monkeys to HHV-6A-mediated inhibition}

HHV-6A was previously shown to suppress the growth of CCR5-dependent (R5) HIV-1 strains in lymphoid tissue [25]. Since SIV typically depends on CCR5 for infection, we evaluated the sensitivity of SIV isolates derived from singly-infected and HHV-6A-coinfected macaques to inhibition by exogenous HHV-6A. Human lymphoid tissues were infected ex vivo with each of the 7 SIV isolates in the presence or absence of HHV-6A, strain GS. A spectrum of different sensitivities to HHV-6A-mediated inhibition was observed. As typically seen with R5 HIV-1 in this model [25], as well as with the original $\operatorname{SIV}_{\text {smE660 }}$ used for inoculation (not shown), SIV isolates derived from animals \#301 and \#307 (singly SIV-infected) were significantly inhibited by HHV-6A (mean virus replication: $56.1 \pm 24 \%$ $\left(\mathrm{n}=2, \mathrm{P}=4 \times 10^{-2}\right)$ and $38.0 \pm 4 \%\left(\mathrm{n}=3, P=2 \times 10^{-2}\right)$, respectively, relative to $\mathrm{HHV}-6 \mathrm{~A}-\mathrm{untreated}$ controls) (Fig. 2A, B). Of note, neither of these two animals progressed to full-blown AIDS during the 32-month follow-up of the in vivo study [19]. By contrast, the third isolate from the singly-infected group (\#303) showed a partial resistance to HHV-6A (mean replication: $87.3 \pm 11 \%$ in the presence of HHV-6A relative to HHV-6A-untreated controls $(\mathrm{n}=4$, $P=1.6 \times 10^{-1}$ ) (Figure $2 \mathrm{C}$ ). As stated above, macaque \#303 was the only AIDS progressor within the singly SIVinfected group [19].

Strikingly, all the SIV isolates derived from HHV-6A-coinfected animals showed resistance to HHV-6A-mediated inhibition. Two isolates $(\# 313,315)$ replicated at similar levels regardless of the presence of HHV-6A (mean replication: $106 \pm 20 \%\left(\mathrm{n}=5, P=3.6 \times 10^{-1}\right)$ and $103 \pm 38 \%$ $\left(\mathrm{n}=3, P=9.3 \times 10^{-1}\right)$, respectively, relative to controls cultured in the absence of HHV-6A) (Fig. 2D, E), while the other two $(\# 316,317)$ replicated even more vigorously in the presence than in the absence of HHV-6A (mean replication: $267 \pm 80 \%\left(\mathrm{n}=5, P=4 \times 10^{-2}\right)$ and $151 \pm 26 \%(\mathrm{n}$ $=3, P=3 \times 10^{-2}$ ), respectively) (Fig. $2 \mathrm{~F}, \mathrm{G}$ ). Overall, even with the inclusion of the partially resistant isolate \#303, the average level of HHV-6A sensitivity was significantly lower among isolates derived from HHV-6A-coinfected monkeys $\left(P=1 \times 10^{-4}, \mathrm{n}=8\right)$. It has to be emphasized that all the animals in the coinfected group progressed to fullblown AIDS during the 32 months of the in vivo study [19]. These data demonstrated that, upon in vivo coinfec- 

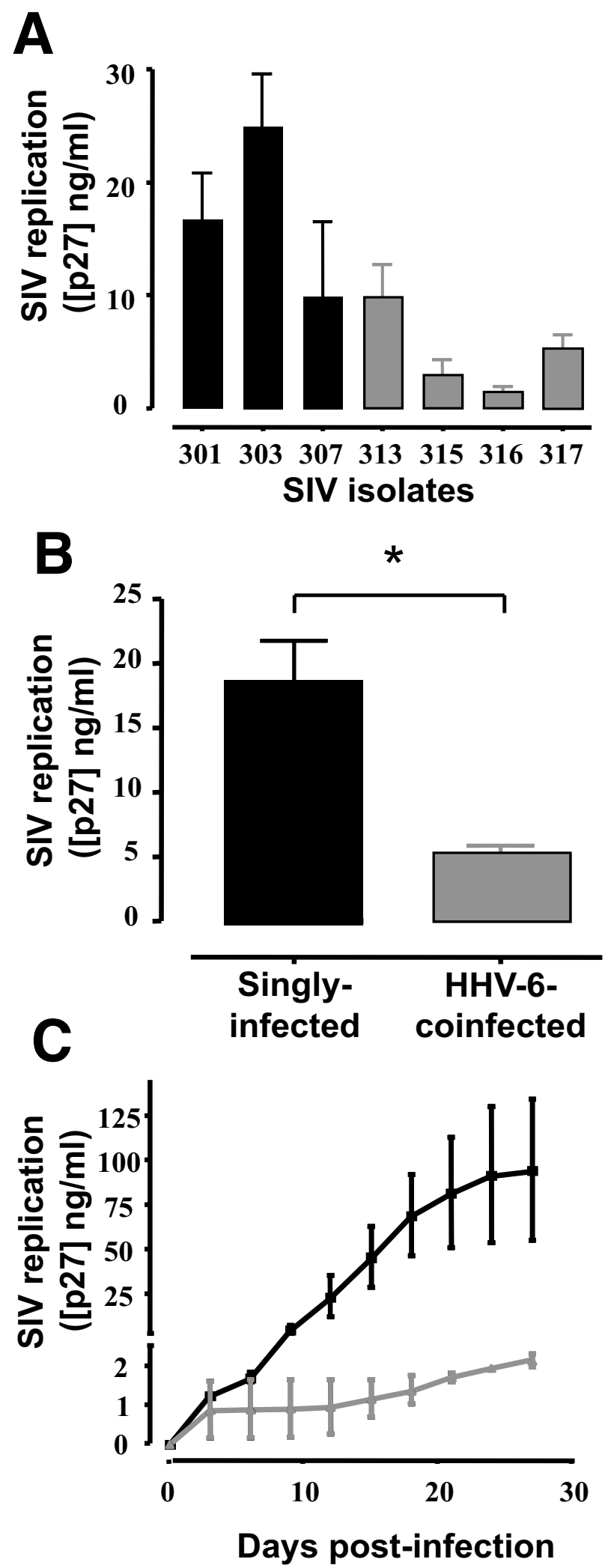

Figure I (see legend on next page) 
Figure I (see previous page)

Ex vivo infection of lymphoid tissue by SIV isolates obtained from singly-infected or HHV-6A-coinfected

macaques. Blocks of human $(\mathbf{A}, \mathbf{B})$ or macaque $(\mathbf{C})$ lymphoid tissue were inoculated with different SIV isolates, and viral replication was evaluated by measuring the level of p27 antigen accumulated in the culture medium every 3 days over 12 days of culture. For each donor, 27 tissue blocks were inoculated. The data indicate the mean values ( \pm SEM) of SIV replication. A. Replication in human lymphoid tissue of SIV isolated from singly-infected macaques $(\# 30 \mathrm{I} n=1 \mathrm{I} ; \# 303 \mathrm{n}=15 ; \# 307, \mathrm{n}=12$ ) and HHV-6A-coinfected macaques (\#3I3, $\mathrm{n}=15$; \#3I5, $\mathrm{n}=11$; \#3I6, $\mathrm{n}=15 ; \# 317, \mathrm{n}=13$ ). B. Comparison of the viral replication levels in tissues infected SIV isolates derived from singly-infected animals $(n=37)$ versus those derived from HHV-6Acoinfected animals $(n=5 I)$. The data represent the mean level of replication $( \pm$ SEM) for all the isolates tested in each group. $*$ $=P<0.00 \mathrm{I}$. C. Replication of SIV \#303, derived from a singly-infected animal (black line), and SIV \#3 I6, derived from an HHV6A-coinfected animal (grey line), in macaque lymphoid tissue $(n=3)$.

tion with HHV-6A, SIV evolved to develop resistance to the inhibitory effects of HHV-6A.

\section{Resistance of SIV isolates derived from HHV-6A-coinfected monkeys to RANTES-mediated inhibition}

We previously demonstrated that HHV-6A induces a dramatic upregulation of RANTES, which could explain the selective suppression of R5 HIV-1 isolates documented in HHV-6A-coinfected human lymphoid tissue ex vivo [25]. Thus, we compared the sensitivities of SIV isolates obtained from singly-infected and HHV-6A-coinfected macaques to RANTES-mediated inhibition. Donormatched blocks of human lymphoid tissues were infected with the 7 SIV isolates in the presence or absence of exogenous RANTES at $100 \mathrm{nM}$, a high dose that was previously determined to inhibit by more than $95 \%$ the growth of a reference R5 HIV-1 isolate (SF162) in this model (not shown). RANTES was maintained at the same concentration throughout the entire time of the experiments (12 days). Among the three SIV isolates derived from singlyinfected macaques, two (\#301, 307) were sensitive to RANTES-mediated inhibition (mean replication in the presence of $100 \mathrm{nM}$ RANTES: $58.1 \pm 12 \%(\mathrm{n}=14, P=4.2$ $\left.\times 10^{-2}\right)$ and $67.8 \pm 12 \%\left(\mathrm{n}=13, P=4.8 \times 10^{-2}\right)$, respectively, relative to controls) (Fig. $2 \mathrm{~A}, \mathrm{~B}$ ), while the third (\#303), which had shown partial resistance to HHV-6A, also had a decreased sensitivity to RANTES (mean replication: $75.4 \pm 10 \%$ relative to control) (Fig. $2 \mathrm{C}$ ). In contrast, all the SIV isolates derived from HHV-6A-coinfected animals were resistant to inhibition by RANTES at the dose used: two $(\# 313,315)$ replicated at similar levels in the presence or absence of exogenous RANTES (mean replication: $82 \pm 17 \%\left(\mathrm{n}=11, \mathrm{P}=3.5 \times 10^{-1}\right)$ and $102 \pm 33 \%(\mathrm{n}$ $=4, P=9.5 \times 10^{-1}$ ), respectively) (Fig. $\left.2 \mathrm{D}, \mathrm{E}\right)$, while the remaining two $(\# 316,317)$ replicated even more vigorously in the presence of RANTES (mean replication level: $150.2 \pm 34 \%\left(\mathrm{n}=10, P=4 \times 10^{-2}\right)$ and $149.2 \pm 30 \%(\mathrm{n}=$ $\left.7, P=2 \times 10^{-1}\right)$, respectively, relative to untreated controls) (Fig. 2F, G). Of note, the latter two isolates were the same that grew more efficiently in the presence of HHV-6A, corroborating the concept that RANTES induction is a potential mechanism of modulation of SIV replication by HHV-
6A. Overall, the average sensitivity to RANTES-mediated inhibition between isolates derived from singly-infected and HHV-6A-coinfected animals was significantly different $\left(P=5 \times 10^{-5}\right)$.

\section{Coreceptor-usage phenotype of SIV isolates derived from singly-infected and HHV-6A-coinfected macaques}

Next, we aimed to determine whether the RANTES resistance/inducibility developed by SIV in HHV-6A-coinfected animals was associated with an altered coreceptor usage. First, all SIV isolates were tested for their ability to infect cells from a healthy, HIV-1-seronegative human subject homozygous for the CCR5- $\Delta 32$ deletion. As shown in Table 1, none of the isolates was able to replicate in CCR5$\Delta 32^{+/+} \mathrm{CD} 4^{+} \mathrm{T}$ cells with the only exception of isolate \#303. This isolate was the only one within the group obtained from singly SIV-infected monkeys to show partial resistance to HHV-6A- and RANTES-mediated inhibition. These results suggested that in this animal (the only AIDS progressor in the singly-infected group), SIV had evolved to use alternative coreceptors during the progression of the disease.

To more precisely characterize the coreceptors used by the 7 SIV isolates, we tested their ability to grow in a human osteosarcoma cell line (Ghost) engineered to express several chemokine receptors that can be used as coreceptors by HIV-1 and SIV, including Bonzo, CX ${ }_{3} \mathrm{CR} 1, \mathrm{CCR} 2 \mathrm{~b}$, CCR3, CCR4, CCR6 and CCR8. Table 1 shows that none of the isolates, including \#303, had the ability to grow in CXCR4-expressing Ghost cells. Of note, all the isolates were able to use, with variable efficiency, some of the minor coreceptors, but this ability did not permit to differentiate the two groups of isolates, suggesting that their differential sensitivity to HHV-6A- or RANTES-mediated inhibition could not be ascribed to the use of alterative coreceptors. 
A

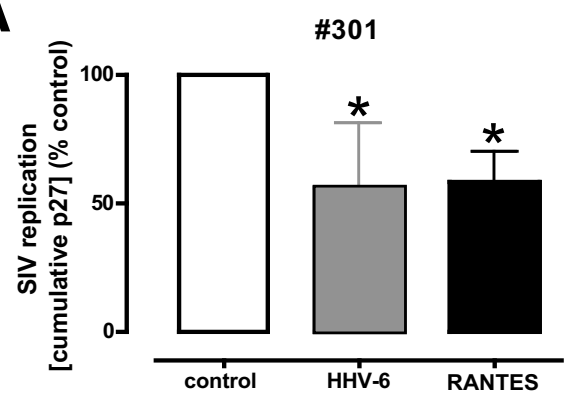

C

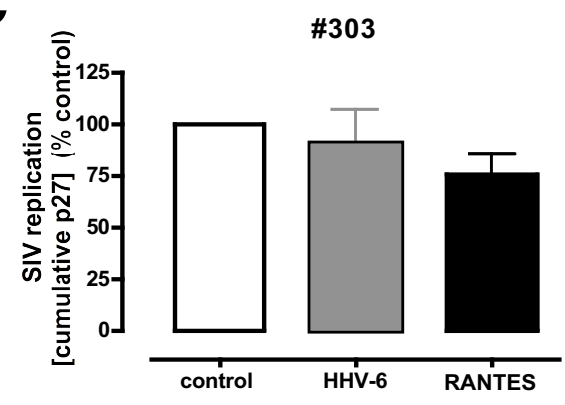

D

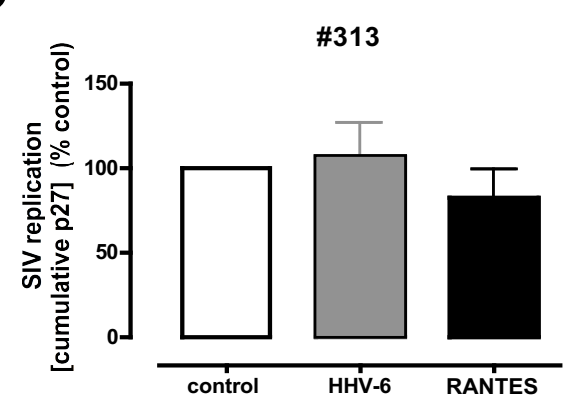

$\mathbf{F}$

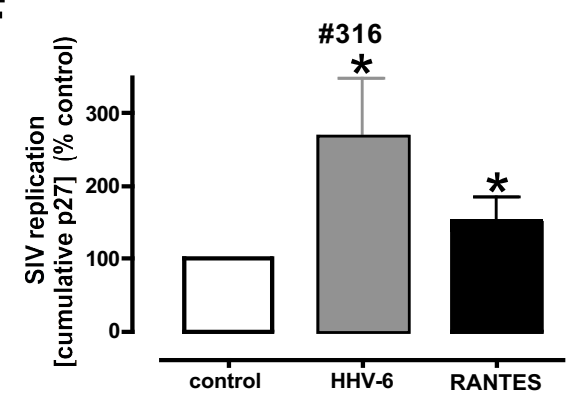

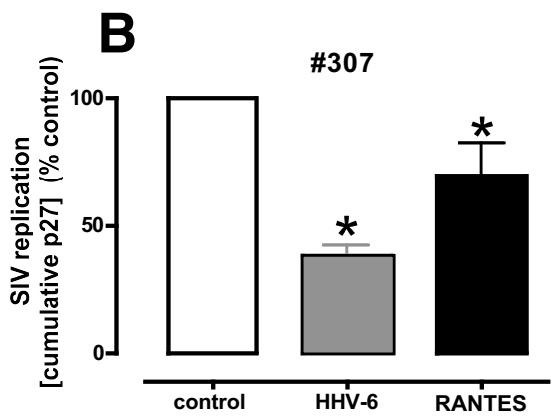
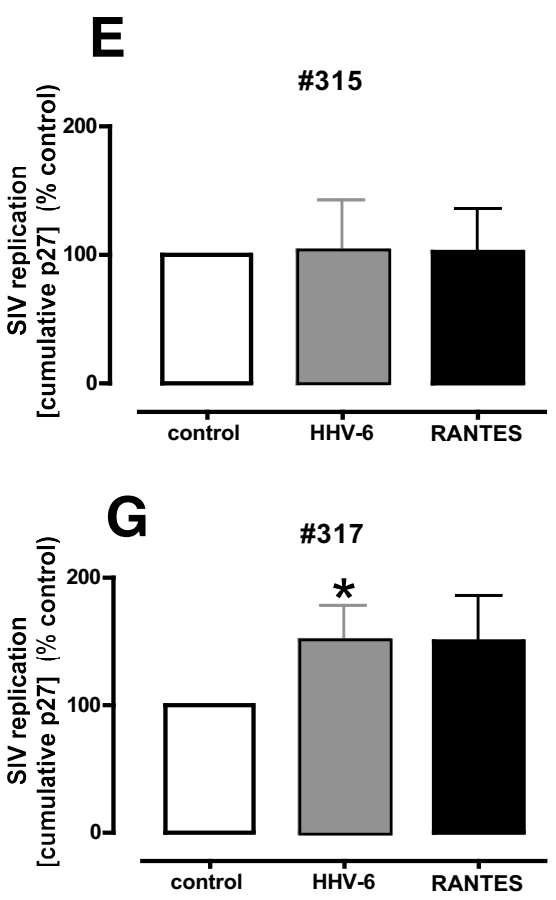

Figure 2

Sensitivity of SIV isolates derived from singly-infected and HHV-6A-coinfected macaques to RANTES- and HHV-6A-mediated inhibition. Blocks of human lymphoid tissues were infected with SIV isolates or coinfected with HHV$6 \mathrm{~A}$. Tissues were cultured with or without exogenous RANTES (I00 nM). The data indicate means $( \pm \mathrm{SEM})$ of cumulative viral replication levels expressed as percent of the levels measured in untreated controls. As expected in this model system, the range of SIV replication in different donor tissues was extremely variable (range: $150-19,000 \mathrm{pg} / \mathrm{ml}$ of p27 antigen). * = Statistically significant difference from the control. A-C. SIV isolates derived from singly SIV-infected animals. A: \#30I $(2 \leq n \leq 4)$; B: \#307 $(2 \leq n \leq 6)$; C: \#303 $(4 \leq n \leq 12)$. D-G. SIV isolates derived from HHV-6A-coinfected animals. D: \#3I3 $(4 \leq n \leq I I)$; E: $\# 315$ ( $2 \leq n \leq 4)$; F: \#3I6 (3 $\leq n \leq 10)$; G: \#3I7 ( $\leq n \leq 7)$. 
Table I: Replication of SIV isolates derived from macaques infected with SIV alone or coinfected with SIV and HHV-6A in primary human $T$ cells and coreceptor-transfected Ghost cell lines.

\begin{tabular}{|c|c|c|c|c|c|c|c|c|c|c|}
\hline \multirow[t]{2}{*}{ Isolates } & \multicolumn{2}{|c|}{ Primary cells } & \multicolumn{8}{|c|}{ Ghost cells expressing: } \\
\hline & Normal PBMC & $\Delta 32^{+/+} \mathrm{CD}^{+}$ & BONZO & $\mathrm{CX}_{3} \mathrm{CRI}$ & CCR2 & CCR3 & CCR4 & CCR6 & CCR8 & CXCR4 \\
\hline 301 & + & - & + & + & - & - & + & - & - & - \\
\hline 303 & + & ++ & + & + & - & + & + & - & - & - \\
\hline 307 & ++ & - & ++ & ++ & ++ & ++ & ++ & - & - & - \\
\hline 313 & + & - & - & + & - & - & + & + & - & - \\
\hline 315 & + & - & + & - & + & - & - & - & + & - \\
\hline 316 & + & - & - & + & + & - & ++ & - & - & - \\
\hline 317 & + & - & - & ++ & + & + & + & - & + & - \\
\hline BaL & +++ & n.d & - & - & - & - & + & - & + & - \\
\hline LAV & +++ & n.d & + & - & - & + & - & ++ & +++ & +++ \\
\hline
\end{tabular}

The reference HIV-I isolates BaL (R5) and LAV (X4) were tested in parallel as controls.

- = no replication; + = weak replication; $++/+++=$ strong replication; $n . d=$ not determined.

\section{Differential cytokine-inductive capacity of SIV isolates derived from singly-infected and HHV-6A-coinfected macaques}

To further investigate the mechanisms underlying the altered replicative capacity of the SIV isolates obtained from HHV-6A-coinfected macaques, we compared the profiles of cytokine secretion in culture medium of donormatched lymphoid tissues $(\mathrm{n}=5)$ infected with SIV isolates derived from singly-infected vs. HHV-6A-coinfected monkeys. The concentration of 17 cytokines was measured using a multiplex bead-based assay. For 15 cytokines, multiple comparison analysis by 2-way ANOVA showed no significant differences between tissues infected with the two groups of SIV isolates (Table 2). By contrast, the

Table 2: Cytokine production in lymphoid tissue infected with SIV derived from macaques infected with SIV alone or coinfected with SIV and HHV-6A.

\begin{tabular}{lccc}
\hline & Singly SIV-infected & HHV-6A-coinfected & P value \\
\hline IL-I $\alpha$ & $5.88 \pm 0.48^{*}$ & $6.37 \pm 0.66$ & 0.84 \\
IL-I $\beta$ & $3.02 \pm 0.37$ & $3.59 \pm 0.50$ & 0.41 \\
IL-2 & $6.55 \pm 0.85$ & $4.61 \pm 0.56$ & $\mathbf{0 . 0 4 * *}$ \\
IL-4 & $5.22 \pm 0.52$ & $5.84 \pm 0.94$ & 0.59 \\
IL-7 & $2.87 \pm 0.35$ & $2.87 \pm 0.48$ & 0.99 \\
IL-I2 & $2.51 \pm 0.46$ & $3.24 \pm 0.46$ & 0.29 \\
IL-I5 & $1.17 \pm 0.18$ & $1.00 \pm 0.11$ & 0.11 \\
IL-I6 & $6.02 \pm 3.14$ & $5.78 \pm 0.31$ & 0.61 \\
MIP-I $\alpha$ & $4.21 \pm 0.32$ & $4.69 \pm 0.44$ & 0.41 \\
MIP-I $\beta$ & $4.01 \pm 0.29$ & $4.21 \pm 0.32$ & 0.65 \\
RANTES & $2.57 \pm 0.23$ & $3.09 \pm 0.23$ & 0.26 \\
IFN- $\gamma$ & $2.44 \pm 0.28$ & $4.69 \pm 0.73$ & $\mathbf{0 . 0 2 * *}$ \\
TNF- $\alpha$ & $1.66 \pm 0.21$ & $1.67 \pm 0.26$ & 0.98 \\
GM-CSF & $31.79 \pm 0.58$ & $33.48 \pm 5.07$ & 0.80 \\
IPI0 & $22.95 \pm 4.33$ & $30.36 \pm 6.20$ & 0.45 \\
MIG & $17.38 \pm 0.12$ & $20.90 \pm 3.16$ & 0.37 \\
SDF-I $\beta$ & $49.77 \pm 7.82$ & $47.26 \pm 5.32$ & 0.78 \\
& & &
\end{tabular}

levels of IL-2 and IFN- $\gamma$, two cytokines that effectively modulate HIV/SIV replication, were significantly different between the two groups. As shown in Table 2, the production of IL-2 was higher in tissues infected with SIV derived from singly-infected animals $\left(P=4.8 \times 10^{-2}\right)$; conversely, the production of IFN- $\gamma$ was higher in tissues infected with SIV derived from HHV-6A-coinfected animals $(P=1.8 \times$ $10^{-2}$ ). Of note, the two groups of isolates did not differ in their ability to induce RANTES, further confirming the lack of HHV-6 contamination of our SIV stocks. This analysis demonstrated that the two groups of SIV isolates possess distinctive biological features, suggesting potential mechanisms for their differential replication capacity.

Since the 4 SIV isolates derived from HHV-6A-coinfected animals exhibited different degrees of RANTES resistance, we compared the cytokine profiles in tissues infected with the two RANTES-resistant isolates (\#313, 315) vs. those infected with the two RANTES-inducible isolates (\#316, 317 ). As shown in Figure 3A, the levels of IL-2 were significantly lower upon infection with RANTES-inducible isolates $(2.4 \pm 0.9 \mathrm{ng} / \mathrm{ml} ; \mathrm{n}=5)$ than with RANTES-resistant isolates $(5.7 \pm 0.5 \mathrm{ng} / \mathrm{ml} ; \mathrm{n}=10)\left(P=4 \times 10^{-2}\right)$. Likewise, the levels of IL-12 were lower in tissues infected with RANTES-inducible isolates $(2.2 \pm 0.4 \mathrm{ng} / \mathrm{ml} ; \mathrm{n}=8$ vs. 4.2 $\pm 0.7 \mathrm{ng} / \mathrm{ml} ; \mathrm{n}=8 ; P=1 \times 10^{-2}$ ) (Fig. $3 \mathrm{~B}$ ). By contrast, the levels of SDF-1 $\beta$ were higher in tissues infected with RANTES-inducible isolates $(58.3 \pm 0.5 \mathrm{ng} / \mathrm{ml} ; \mathrm{n}=8)$ than with RANTES-resistant isolates $(36.2 \pm 0.8 \mathrm{ng} / \mathrm{ml} ; \mathrm{n}=8)$ $\left(P=7 \times 10^{-2}\right)$ or with isolates derived from singly-infected animals $(49.8 \pm 0.8 \mathrm{ng} / \mathrm{ml} ; \mathrm{n}=13)\left(P=5 \times 10^{-2}\right)$ (Fig. $\left.3 \mathrm{D}\right)$. A similar trend, albeit not statistically significant, was observed for IFN- $\gamma$ (Fig. 3B). These results confirmed the inherent biological alterations of SIV after in vivo passage in the presence of HHV-6A, suggesting that the RANTESinducible isolates, which showed the highest ability to 

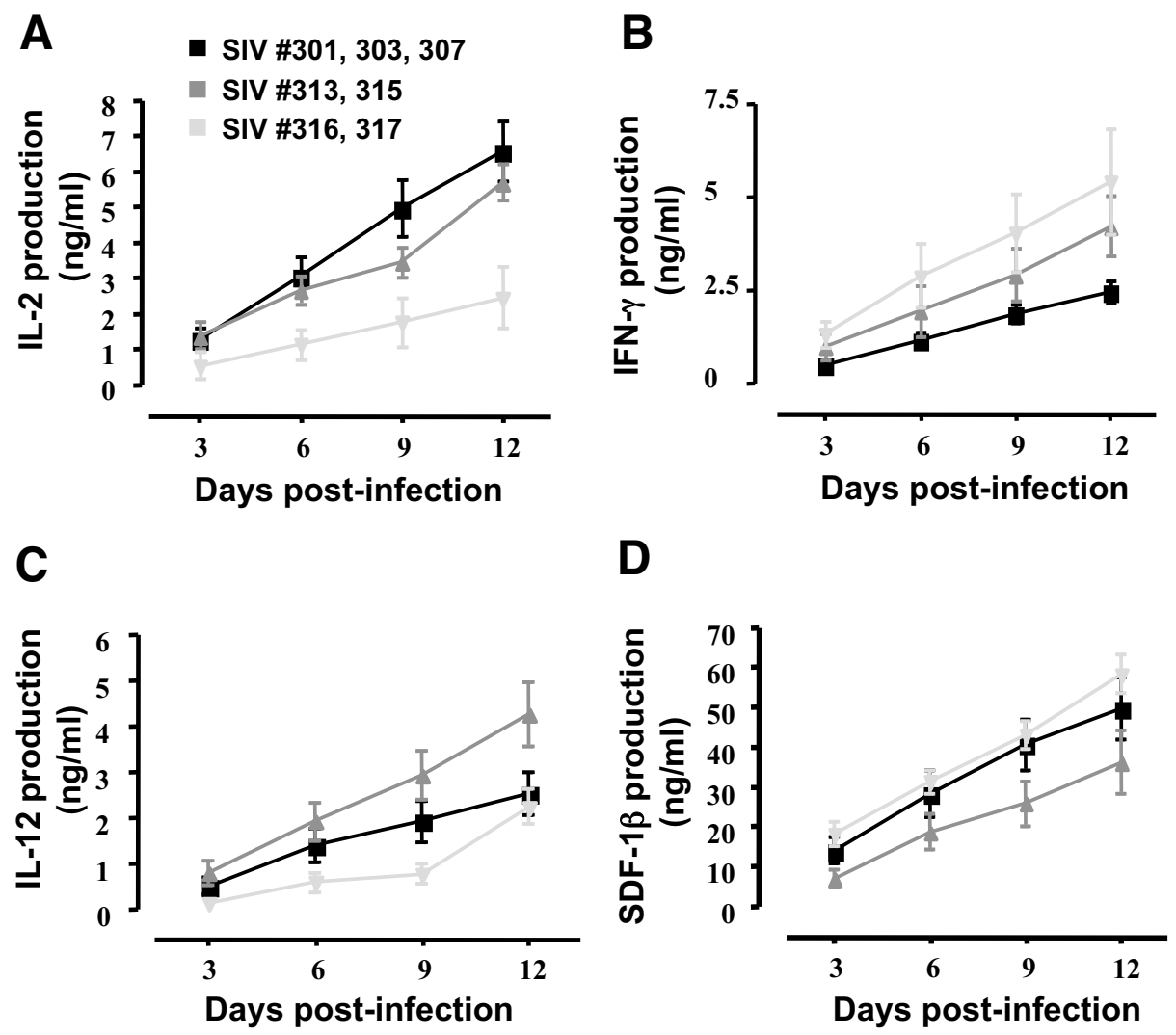

Figure 3

Cytokine secretion profiles in human lymphoid tissue infected with SIV isolates obtained from singly-infected and HHV-6A-coinfected macaques. Blocks of human lymphoid tissue were infected with SIV isolates. The concentrations of IL-2 (A), IFN- $\gamma(\mathbf{B})$, IL-I 2 (C), and SDF-I $\beta$ (D) were measured in conditioned culture medium from 27 tissue blocks using a multiplex bead-based assay. The data indicate the mean $( \pm$ SEM) concentrations of each cytokine accumulated in the culture medium over 12 days in experiments with tissues from 5 human lymphoid tissue donors. Black: SIV from singly-infected macaques (\#30I, 303, 307); dark grey: RANTES-resistant SIV isolated from HHV-6A-coinfected macaques (\#3 I3, 3I5); light grey: RANTES-inducible SIV isolated from HHV-6A-coinfected macaques (\#3 I6, 3I7).

suppress IL-2 and induce IFN- $\gamma$, may represent a more advanced evolutionary stage than the RANTES-resistant isolates.

\section{Discussion}

Progression toward full-blown AIDS is often associated with the evolution of HIV-1 toward increased virulence or pathogenicity. In a proportion of patients, HIV-1 acquires the ability to use CXCR4 as a coreceptor, becoming resistant to the inhibitory effects of endogenous CCR5-binding chemokines, such as RANTES, that are believed to play a critical role in the early containment of HIV-1 replication [26]. This phenotypic switch is typically accompanied by an accelerated loss of CD4+ T cells. Strikingly, the emergence of more aggressive viral strains, including RANTESresistant variants, has also been documented in patients who progress to full-blown AIDS without a change in viral coreceptor usage [27-29], focusing attention on the role played by RANTES resistance as a virulence factor for HIV1. The mechanisms driving the in vivo evolution of HIV-1 are poorly understood at present, although an increase in the levels of endogenous RANTES, as typically occurs in inflamed lymphoid tissues, is likely to play a role. In this paper, we investigated these mechanisms taking advantage of the model of in vivo coinfection with SIV and HHV$6 \mathrm{~A}$ in macaques [19] and the ex vivo model of human and macaque lymphoid tissue explant systems [21].

Our results indicate that SIV isolates obtained from HHV6A-coinfected animals underwent a dramatic biological evolution in vivo, with the emergence of viral strains with a reduced sensitivity to RANTES-mediated inhibition, despite the maintenance of a strict dependence on CCR5 as a coreceptor. In two animals, the SIV isolates even 
exhibited a RANTES-inducible phenotype, as they replicated more vigorously in the presence than in the absence of exogenous RANTES. We recognize that the study of a larger number of animals would provide additional ground to the conclusions of this study, but unfortunately studies in nonhuman primates are often hindered by the limited number of animals that can be enrolled. Nevertheless, we believe that the observation that 4 out of 4 HHV-6A-coinfected animals harbored RANTES-resistant SIV strains after 1 year of infection corroborates the conclusions of this study even in the absence of a larger sampling size. Since our experiments were performed using RANTES at a single dose, albeit high $(100 \mathrm{nM})$, we cannot formally exclude that some SIV isolates would be inhibited at even higher chemokine concentrations, thus showing a reduced sensitivity to RANTES rather than bona fide resistance. However, the physiological relevance of RANTES concentrations above $100 \mathrm{nM}$ remains to be established. Moreover, at least with the two SIV isolates with a RANTES-inducible phenotype $(\# 316,317)$, the possibility of detecting inhibitory effects at higher chemokine concentrations appears unlikely. Consistent with the RANTES-inductive activity of HHV-6A $[25,30]$, the two RANTES-resistant isolates were also resistant to HHV6A-mediated inhibition, whereas the two RANTES-inducible isolates were also HHV-6A-inducible. These results suggest that in vivo, under the selective pressure of the RANTES-rich microenvironment created by HHV-6A, SIV was driven to acquire a RANTES-resistant phenotype, thus bypassing an important mechanism of virus control.

Somewhat surprisingly, resistance to RANTES was associated with a diminished replicative capacity of SIV. This finding may appear counterintuitive considering the accelerated progression of SIV disease that occurred in HHV-6A-coinfected animals. However, an optimal fitness for survival in a high-RANTES environment in vivo does not necessarily imply an equal fitness for replication in an ex vivo culture system in the presence of lower RANTES concentrations. Most likely, the acquisition of RANTES resistance/inducibility was a necessary condition for SIV to maintain sufficient levels of replication in the highRANTES environment induced by HHV-6A coinfection in vivo. Interestingly, we found that RANTES-resistant SIV isolates suppressed the secretion of IL-2 while increasing the production of IFN- $\gamma$, two effects that may help to explain their lowered replicative capacity in lymphoid tissues. This altered cytokine profile was particularly pronounced for the two RANTES-inducible isolates, suggesting that SIV evolution in HHV-6A-coinfected animals was a progressive phenomenon. Of note, a similar phenotype has been linked to high antigenic loads and defective antigen clearance in HIV-1 infected patients, leading to faster disease progression [31,32]. Furthermore, replication of RANTES-inducible SIV isolates was also associated with suppression of IL-12, a critical cytokine in the development of effective cell-mediated immune responses, particularly Th1-polarized responses that play an essential role in the clearance of viral infections. This could represent an additional mechanism of SIV-disease acceleration in HHV-6A-coinfected animals.

The inability of SIV isolates derived from HHV-6A-coinfected macaques to grow in CCR5- $\Delta 32^{+/+} \mathrm{CD} 4{ }^{+} \mathrm{T}$ cells unambiguously demonstrated their strict dependence on the CCR5 coreceptor for entry, in spite of their RANTES resistance. This suggested that SIV acquired the ability to interact with CCR5 in a modified fashion, insensitive or even facilitated by the presence of a bound inhibitor. Similar alterations were previously documented for HIV-1 variants selected in vitro for resistance to small-molecule CCR5 inhibitors [33,34]. Some degree of replication in CCR5- $\triangle 32$ PBMC, indicative of alternative coreceptor usage, was instead documented with a single SIV isolate derived from singly-infected macaques (\#303). Noteworthy, this isolate was derived from the only animal in the singly-infected group to progress to full-blown AIDS during the follow-up of the in vivo study [19]. Consistent with an expanded coreceptor usage, this was also the only isolate among those derived from singly-infected animals to show a partial resistance to both HHV-6A- and RANTESmediated inhibition. However, unlike the SIV isolates obtained from HHV-6A-coinfected animals, this virus grew in lymphoid tissue more efficiently than any of the other isolates tested. Altogether, these results indicate that also in animal \#303 progression to AIDS was associated with SIV evolution toward RANTES resistance, but this evolution followed a different pathway than in animals coinfected with HHV-6A. Regardless, the rapid disease progression observed in this animal reinforces the concept that the emergence of RANTES-resistant viral variants may constitute a critical virulence factor for primate immunodeficiency viruses to evade an effective mechanism of host antiviral defense.

\section{Conclusion}

In conclusion, our study illustrates a novel mechanism whereby coinfection with a putative AIDS-progression cofactor, the T-lymphotropic herpesvirus HHV-6A, may affect the in vivo evolution of SIV leading to an accelerated development of AIDS. Understanding the complex interactions between HHV-6A and primate immunodeficiency viruses may provide important information not only for a deeper understanding of AIDS pathogenesis, but also for the development of novel preventive and therapeutic strategies against HIV-1.

\section{Abbreviations}

(AIDS): Acquired immunodeficiency syndrome; (HIV-1): human immunodeficiency virus type 1 ; (SIV): simian 
immunodeficiency virus; (HHV-6A): human herpesvirus 6A; (RANTES): regulated upon activation, normal $\mathrm{T}$ expressed and presumably secreted; (R5): CCR5-dependent; (PBMC): peripheral blood mononuclear cells.

\section{Competing interests}

The authors declare that they have no competing interests.

\section{Authors' contributions}

$\mathrm{AB}$ designed and performed experiments, analyzed data, wrote manuscript; JCG designed experiments and analyzed data; AL performed experiments and analyzed data; $\mathrm{CV}$ analyzed data; PDM performed experiments and helped in the design of the study; RCG designed research and analyzed data; LBM designed research and analyzed data; PL designed research, analyzed data and wrote manuscript.

\section{Acknowledgements}

We are grateful to Dr. M. Santi and the entire staff of the Department of Anatomic Pathology of Children's National Medical Center in Washington, DC, for their generous assistance in obtaining human tonsil tissues. This research was supported in part by the Intramural Research Program of the $\mathrm{NICHD}, \mathrm{NIH}$, Bethesda, MD, the EU Biomed-2 Programme, Brussels (grant no. BMH4CT96I30I to P.L.), and the ISS Italian AIDS Program, Rome (grants no. 40B.57, 50C.17, 50D.17 and 50F.23 to P.L.).

\section{References}

I. Gallo RC, Montagnier L: The discovery of HIV as the cause of AIDS. N Engl J Med 2003, 349:2283-2285.

2. Beilke MA, Greenspan DL, Impey A, Thompson J, Didier PJ: Laboratory study of HIV-I and HTLV-I/II coinfection. J Med Virol I 994 44:132-143.

3. Beilke MA, Theall KP, O'Brien M, Clayton IL, Benjamin SM, Winsor $\mathrm{EL}$, Kissinger PJ: Clinical outcomes and disease progression among patients coinfected with HIV and human T lymphotropic virus types I and 2. Clin Infect Dis 2004, 39:256-263.

4. Kaiser T, Tillmann HL: GB virus $\mathbf{C}$ infection: is there a clinical relevance for patients infected with the human immunodeficiency virus? AIDS Rev 2005, 7:3-I2.

5. Stapleton JT, Williams CF, Xiang J: GB virus type C: a beneficial infection? J Clin Microbiol 2004, 42:3915-3919.

6. Margolis L: Cytokines - strategic weapons in germ warfare? Nat Biotechnol 2003, 21:15-16.

7. Lusso P, Gallo RC: Human herpesvirus 6 in AIDS. Immunol Today 1995, 16:67-7|.

8. Lusso P, Ensoli B, Markham PD, Ablashi DV, Salahuddin SZ, Tschachler E, Wong-Staal F, Gallo RC: Productive dual infection of human CD4+ T lymphocytes by HIV-I and HHV-6. Nature 1989, 337:370-373.

9. Ensoli B, Lusso P, Schachter F, Josephs SF, Rappaport J, Negro F, Gallo RC, Wong-Staal F: Human herpes virus-6 increases HIV-I expression in co-infected $\mathrm{T}$ cells via nuclear factors binding to the HIV-I enhancer. Embo / 1989, 8:3019-3027.

10. Lusso P, De Maria A, Malnati M, Lori F, DeRocco SE, Baseler M, Gallo RC: Induction of CD4 and susceptibility to HIV-I infection in human CD8+ T lymphocytes by human herpesvirus 6. Nature 1991, 349:533-535.

II. Lusso P, Malnati MS, Garzino-Demo A, Crowley RW, Long EO, Gallo RC: Infection of natural killer cells by human herpesvirus 6 . Nature 1993, 362:458-462.

12. Flamand L, Gosselin J, D'Addario M, Hiscott J, Ablashi DV, Gallo RC, Menezes J: Human herpesvirus 6 induces interleukin-I beta and tumor necrosis factor alpha, but not interleukin-6, in peripheral blood mononuclear cell cultures. J Virol 1991, 65:5105-5110.
13. Corbellino M, Lusso P, Gallo RC, Parravicini C, Galli M, Moroni M: Disseminated human herpesvirus 6 infection in AIDS. Lancet 1993, 342: 1242.

14. Knox KK, Carrigan DR: Disseminated active HHV-6 infections in patients with AIDS. Lancet 1994, 343:577-578.

15. Secchiero P, Carrigan DR, Asano Y, Benedetti L, Crowley RW, Komaroff AL, Gallo RC, Lusso P: Detection of human herpesvirus 6 in plasma of children with primary infection and immunosuppressed patients by polymerase chain reaction. J Infect Dis 1995, I71:273-280.

16. Knox KK, Carrigan DR: Active HHV-6 infection in the lymph nodes of HIV-infected patients: in vitro evidence that HHV6 can break HIV latency. J Acquir Immune Defic Syndr Hum Retrovirol 1996, I I:370-378.

17. Emery VC, Atkins MC, Bowen EF, Clark DA, Johnson MA, Kidd IM, McLaughlin JE, Phillips AN, Strappe PM, Griffiths PD: Interactions between beta-herpesviruses and human immunodeficiency virus in vivo: evidence for increased human immunodeficiency viral load in the presence of human herpesvirus 6. J Med Virol 1999, 57:278-282.

18. Kositanont U, Wasi C, Wanprapar N, Bowonkiratikachorn P, Chokephaibulkit K, Chearskul S, Chimabutra K, Sutthent R, Foongladda S, Inagi R, et al.: Primary infection of human herpesvirus 6 in children with vertical infection of human immunodeficiency virus type I. J Infect Dis 1999, I80:50-55.

19. Lusso P, Crowley RW, Malnati MS, Di Serio C, Ponzoni M, Biancotto A, Markham PD, Gallo RC: Human herpesvirus 6A accelerates AIDS progression in macaques. Proc Natl Acad Sci USA 2007, 1 04:5067-5072.

20. Locatelli G, Santoro F, Veglia F, Gobbi A, Lusso P, Malnati MS: Realtime quantitative PCR for human herpesvirus 6 DNA. J Clin Microbiol 2000, 38:4042-4048.

21. Glushakova S, Baibakov B, Margolis LB, Zimmerberg J: Infection of human tonsil histocultures: a model for HIV pathogenesis. Nat Med 1995, I:I320-1322.

22. Glushakova S, Baibakov B, Zimmerberg J, Margolis LB: Experimental HIV infection of human lymphoid tissue: correlation of CD4+ T cell depletion and virus syncytium-inducing/non-syncytium-inducing phenotype in histocultures inoculated with laboratory strains and patient isolates of HIV type I. AIDS Res Hum Retroviruses 1997, 13:461-471.

23. Salahuddin SZ, Ablashi DV, Markham PD, Josephs SF, Sturzenegger S, Kaplan M, Halligan G, Biberfeld P, Wong-Staal F, Kramarsky B, et al: Isolation of a new virus, HBLV, in patients with lymphoproliferative disorders. Science 1986, 234:596-601.

24. Margolis LB, Glushakova S, Grivel JC, Murphy PM: Blockade of CC chemokine receptor 5 (CCR5)-tropic human immunodeficiency virus-I replication in human lymphoid tissue by $\mathrm{CC}$ chemokines. J Clin Invest 1998, 10 I:1876-1880.

25. Grivel JC, Ito Y, Faga G, Santoro F, Shaheen F, Malnati MS, Fitzgerald W, Lusso P, Margolis L: Suppression of CCR5- but not CXCR4tropic HIV-I in lymphoid tissue by human herpesvirus 6. Nat Med 200I, 7:1232-1235.

26. Lusso P: HIV and the chemokine system: 10 years later. $E M B O$ J 2006, 25:447-456.

27. Karlsson I, Antonsson L, Shi Y, Karlsson A, Albert J, Leitner T, Olde $B$, Owman C, Fenyo EM: HIV biological variability unveiled: frequent isolations and chimeric receptors reveal unprecedented variation of coreceptor use. Aids 2003, 17:256|-2569.

28. Koning FA, Koevoets C, Vorst TJ van der, Schuitemaker H: Sensitivity of primary R5 HTV-I to inhibition by RANTES correlates with sensitivity to small-molecule R5 inhibitors. Antivir Ther 2005, 10:231-237.

29. Koning FA, Kwa D, Boeser-Nunnink B, Dekker J, Vingerhoed J, Hiemstra $H$, Schuitemaker $H$ : Decreasing sensitivity to RANTES (regulated on activation, normally $\mathrm{T}$ cell-expressed and secreted) neutralization of CC chemokine receptor 5-using, non-syncytium-inducing virus variants in the course of human immunodeficiency virus type I infection. J Infect Dis 2003, I 88:864-872.

30. Grivel JC, Santoro F, Chen S, Faga G, Malnati MS, Ito Y, Margolis L, Lusso P: Pathogenic effects of human herpesvirus 6 in human lymphoid tissue ex vivo. J Virol 2003, 77:8280-8289.

31. Harari A, Vallelian F, Meylan PR, Pantaleo G: Functional heterogeneity of memory CD4 $\mathrm{T}$ cell responses in different conditions 
of antigen exposure and persistence. J Immunol 2005, 174: 1037-1045.

32. Zimmerli SC, Harari A, Cellerai C, Vallelian F, Bart PA, Pantaleo G: HIV-I-specific IFN-gamma/IL-2-secreting CD8 $T$ cells support CD4-independent proliferation of HIV-I-specific CD8 T cells. Proc Natl Acad Sci USA 2005, 102:7239-7244.

33. Kuhmann SE, Pugach P, Kunstman KJ, Taylor J, Stanfield RL, Snyder A, Strizki JM, Riley J, Baroudy BM, Wilson IA, et al:: Genetic and phenotypic analyses of human immunodeficiency virus type I escape from a small-molecule CCR5 inhibitor. J Virol 2004, 78:2790-2807.

34. Trkola A, Kuhmann SE, Strizki JM, Maxwell E, Ketas T, Morgan T, Pugach P, Xu S, Wojcik L, Tagat J, et al.: HIV-I escape from a small molecule, CCR5-specific entry inhibitor does not involve CXCR4 use. Proc Natl Acad Sci USA 2002, 99:395-400.

Publish with Bio Med Central and every scientist can read your work free of charge

"BioMed Central will be the most significant development for disseminating the results of biomedical research in our lifetime. "

Sir Paul Nurse, Cancer Research UK

Your research papers will be:

- available free of charge to the entire biomedical community

- peer reviewed and published immediately upon acceptance

- cited in PubMed and archived on PubMed Central

- yours - you keep the copyright

Submit your manuscript here:

http://www.biomedcentral.com/info/publishing_adv.asp
BiolMedcentral 